\title{
Effectiveness of Nutrition Programs in Increasing Healthy Eating Behaviors among Low Income Women
}

\author{
Rebecca A. Vidourek and Keith A. King \\ University of Cincinnati
}

\begin{abstract}
This article presents a review of the literature regarding nutrition education programs targeting low income women. A total of 15 interventions were found, which met inclusion criteria. Inclusion criteria included publication between January 1, 2001 and January 1, 2007, focus on low income females, focus exclusively on nutrition and improvement of dietary behaviors, publication in English, and intervention took place in the US. The 15 studies meeting the search criteria were, in turn, re-reviewed collectively by the authors. Ten main themes were found: 1) WIC and EFNEP-based interventions, 2) collaborative approaches, 3) theoretical framework, 4) learner-centered, 5) skills-based programs, 6) use of produce coupons or vouchers, 7) computer-based programs, 8) culturally-based interventions, 9) peer teaching, and 10) recommendations to include social support or physical activity. A summary of each was developed and emergent themes were identified. In this manner, effective strategies and lessons learned from the research regarding increasing healthy eating among low income females could be more clearly delineated and discussed. This paper could be quite beneficial to health educators and health researchers interested in increasing healthy dietary practices among low income females.

(C) 2008 Californian Journal of Health Promotion. All rights reserved.

Keywords: nutrition, low income, Women, Infants, and Children (WIC), Stages of Change
\end{abstract}

\section{Introduction}

Poor dietary behaviors are a primary contributor to morbidity and mortality in the US (United States Department of Health and Human Services [USDHHS], 2005). Of the top three leading causes of death in the US (heart disease, cancer and stroke), a sizeable percentage are due in part to unhealthy eating habits (Centers for Disease Control and Prevention [CDC], 1999). Healthy eating habits reduce the risk of several chronic diseases (Willet, et al., 1995) and can decrease overall mortality in women by $11 \%$ (McCullough et al, 2002). Both healthy food choices and the consumption of fewer calories are important steps in decreasing weight and reducing the likelihood of developing coronary heart disease, cancer and stroke (USDHHS, 2005). Research supports a diet high in fruits, vegetables, whole grains, fiber, and lean protein (USDHHS, 2005). Nevertheless, fewer than $25 \%$ of Americans consume five or more servings of fruits and vegetables each day (CDC, 2006).

Under-consumption of fruits, vegetables, and whole grains combined with over-consumption of high fat foods are associated with increased risk for overweight and obesity (USDHHS, 2005). Approximately 65 million American females are classified as overweight or obese (National Center for Health Statistics [NCHS], 2006). Obesity plays a significant role in the development of a variety of morbidities and annually costs the nation over $\$ 115$ billion (CDC, 2006). While genetics can play a role, the problem of obesity ultimately results from consuming more calories than expended through physical activity (USDHHS, 2001b). Since behavioral and environmental factors are significant contributors to overweight and obesity, prevention efforts often center on these two issues. 
Research indicates that healthy food habits differ based on demographic variables (Lullukka, Laaksonen, Rahkonen, Roos, \& Lahelma, 2007). Level of education, income, and gender are all associated with individual eating patterns and behavioral choices. Individuals with lower levels of education are less likely than those with higher levels of education to choose healthy foods (Lullukka, et al., 2007). In fact, education is one of the strongest indicators in predicting healthy nutritional behaviors (Groth, Fagt, \& Brondsted, 2001). Additionally, individuals with high occupational class and high income levels are more likely to report healthy eating behaviors (Irala-Estevez, Groth, Johansson, Oltersdorf, Prattala, \& Martinez-Gonzalez, 2000; Groth et al., 2001; Hulshof, Brussaard, Kruizinga, Telman, \& Lowik, 2003; Martikainen, Brunner, \& Marmot, 2003; Shahar, Shai, Vardi, Shahar, \& Fraser, 2005). Income is directly associated with healthy nutritional behaviors, particularly fruit and vegetable consumption among women (Groth et al., 2001).

Additional research suggests that access to fruits and vegetables is constrained by low income levels, particularly among women (Giskes, Turrell, Patterson, \& Newman, 2002; Kirkpatrick \& Tarasuk, 2003). Such lack of access to healthy foods creates significant policy challenges. Comprehensive policies, which account for economic disparities in accessing healthy foods, are necessary to improve the availability of fruits and vegetables for low income individuals (Drewnowski \& Darmon, 2005). Interestingly, women of lower socioeconomic status are $50 \%$ more likely to be obese than all other individuals (USDHHS, 2001a). Such high obesity rates among low SES women are likely due to the regular consumption of high calorie, high fat foods, and lack of involvement in regular physical activity. Low income women's dietary intakes have also been shown to be sensitive to the depletion of household resources, meaning that as monthly income begins to be used up, there is greater tendency to show moderate or severe food insecurity (Tarasuk, McIntyre, \& Li, 2007). Such insecurity is associated with declines in carbohydrate, vitamin B-6, and fruit and vegetable intakes. In addition, food insecurity may predispose individuals to weight gain, since the lack of income to purchase healthy foods can lead to the over-consumption of less expensive but more energy-dense foods (Drewnowski, 2003; Drewnowski, Darmon, \& Briend, 2004; Drewnowski \& Specter, 2004).

A comprehensive review of the literature revealed no published study that had collectively examined nutrition programs aimed at increasing healthy eating behaviors among low income women. Therefore, the present study was conducted to review the literature regarding nutrition interventions aimed at this group. More specifically, the main research questions were to identify the most commonly used strategies to increase healthy eating habits among low income women and to identify the strategies found to be most effective in modifying dietary habits. A further purpose of the study was to identify lessons learned from the previous studies, points of concern with study findings and current gaps in the research.

\section{Methods}

The present study examined the professional literature regarding the effectiveness of nutrition education programs targeting low income women. The authors conducted a search of CINAHL, Academic Search Premier, Family and Social Studies Worldwide, SocINDEX, MEDLINE databases using the following search terms: nutrition programs, nutrition interventions, nutrition education programs, nutrition education evaluation, low income, women, low income women, food, eating, and nutrition. A total of 950 articles were examined for eligibility $(\mathrm{N}=317$ from CINAHL), $(\mathrm{N}=$ 404 from Academic Search Premier) and ( $\mathrm{N}=$ 229 from Family and Social Studies Worldwide, SocINDEX, and MEDLINE). The study criteria for inclusion were that articles had to: 1) be published between January 1, 2001 and January $1,2007,2)$ focus on general adult population as opposed to adults with certain health disorders (e.g., diabetes, mental health disorders, HIV), 3) focus exclusively on nutrition and improvement of dietary behaviors, 4) be published in English, 5) have a program focused toward low income females, and 6) have the intervention take place 
in the US. Study exclusion criteria included studies published in a language other than English, studies published before January 1, 2001, studies focusing on adults with health disorders, such as diabetes, Alzheimer's, or cancer, and studies focusing on weight loss rather than improving eating habits. A total of 15 studies met the search criteria. The 15 studies meeting the search criteria were in turn rereviewed collectively by the authors. A summary of each was developed and emergent themes were identified. In this manner, effective strategies and lessons learned from the research regarding increasing healthy eating among low income females could be more clearly delineated and discussed.

\section{Results}

As mentioned above, a total of 15 articles met the criteria for study inclusion. Though these articles and programs varied in size, scope and overall description, a series of main themes emerged and key findings were identified as showing effectiveness in increasing healthy eating habits among low income women. A brief summary of the programs included in this study are depicted in Appendix A. The following paragraphs address the main themes shown in these studies to be effective in increasing healthy eating among low income women.

It would be a good idea to underline the "Main Themes throughout the manuscript so that they stand out better. Otherwise it is difficult to know when the next theme begins. Main Theme 1: Use of Women, Infant and Children (WIC) and Expanded Food and Nutrition Education Programs (EFNEP) as Intervention Sites. A number of the studies used WIC and EFNEP as intervention sites since participants in such programs often are low income women. For instance, Conrey, Frongillo, Dollahite, According to APA, should this be spelled out as "and" since it is part of the written text. I think there are at least a few others like this. I will point them out. Furthermore, when more than 6 authors are in one publication, you should just use et al. You can also use et al. when you have cited them once before. \& Griffin (2003) examined changes to a WIC-based farmer's market nutrition program as a means of enhancing participation rates. Specific changes included multi-agency collaboration, increasing quality resources available to program participants, having a project coordinator, and building the capability of local level resources. Researchers employed a quasi-experimental study design. A series of $\$ 2.00$ coupons for a farmer's market were mailed to WIC participants. Program participation was tracked by coupon redemption. Additionally, researchers assessed changes in participation rate after specific changes were made to the program. Results indicated that an additional \$122,931$\$ 316,754$ was spent on fruits and vegetables after the changes were made to the program.

Cason, Scholl, \& Kassab (2002) showed positive impact of using the Expanded Food and Nutrition Education Program (EFNEP) on eating behaviors. WIC sites were one area of focus for the nutrition education provided by these researchers. Similarly, Heneman et al. (2005) found significant increases in fruit consumption in women participating in EFNEP. Results of these programs showed the positive efficacy of using EFNEP and WIC as intervention sites for nutrition education.

Havas, Anliker, Greenberg, Block, Block, Blik, Langenberg, \& DiClemente (2003) evaluated the Maryland WIC Food for Life program aimed at decreasing intake of fat and increase fruit, vegetable, and fiber intake among low income women enrolled in WIC. A total of 1055 women at ten WIC sites served as intervention participants while 1011 women served as controls. Study inclusion criteria were WIC enrolled women or women with children enrolled in WIC, over age 18 , intend to remain with WIC for at least 8 months, speak English, able to participate in monthly nutrition programs, consent to completing pretest and posttest surveys, and are not enrolled or have never been enrolled in WIC's Five-A-Day nutrition education program. The intervention occurred over a period of 6 months and consisted of 5 interactive nutrition programs. Written materials were also given to intervention participants to enhance and highlight program 
focus areas. The intervention was multidimensional and included a video from pilot study participants, a brochure, feedback from Food Frequency Questionnaire, a kick-off, workshops, newsletters, mail packets, invitations, incentives, and phone calls. Results indicated that more than half of women did not attend any educational session conducted at WIC. The intervention group was significantly more likely than the control group to reduce percent of calories from fat $(p<.0001)$, increase intake of fruits and vegetables $(\mathrm{p}<.0003)$ and fiber $(\mathrm{p}<.001)$. (there should be one space between each side of equal, greater than, and less than signs. At one year intervention, reduction in calories from fat and increased intake of fruits and vegetables remained significant. Individuals under 30 years of age and individuals possessing a high school diploma were more likely to report these changes. Individuals who attended multiple educational sessions reported greater levels of self-efficacy than individuals who attended one or zero sessions. The authors report several limitations for this study. First, all data from the study was self-reported. Next, follow-up data was not collected from all intervention participants. Few implications for research and practice are offered. The authors feel the study warrants replication at other WIC sites or in similar settings.

Boyd \& Windsor (2003) utilized the WIC program to deliver a nutrition education program to low income women who were pregnant. Intervention participants $(\mathrm{N}=120)$ who completed the program showed significantly greater increases than those who did not complete the program in nutrition knowledge and eating behaviors. Bhargava and Hays (2004) recommended continued research into the effectiveness of nutrition programs based within government organizations, such as WIC.

Main Theme 2: Use of Collaborative Efforts to Impact Change. Collaborative efforts were shown on a variety of different levels but most notably among community-based efforts, governmental programs, statewide initiatives and multi-agency interventions. Emphasis on collaborating and cooperating with other groups was an important factor toward program effectiveness in several of the studies examined. For instance, Conrey, Frongillo, Dollahite, \& Griffin (2003) utilized multi-agency collaboration to enhance fruit and vegetable purchases in a WIC-based farmer's market nutrition program. Success of the program was largely due to the ability of coordinating a nutrition program on a state and local level through collaborative efforts.

Ikeda, Phan, Nguyen, \& Mitchell (2002) also used collaborative efforts to increase healthy eating habits among low income women, with a specific focus on Vietnamese women immigrants in the US. The intervention utilized a statewide advisory council to guide the project, translate educational components and effectively deliver the program to Vietnamese women eligible to received Women, Infant, and Children (WIC) benefits. Results indicated that the intervention group was significantly more likely than the control group to follow recommended dietary guidelines for servings and food groups as well as increases in intake of calcium, riboflavin, vitamin $\mathrm{B}$, and potassium ( $\mathrm{p}$ $<.05)$. Boyd and Windsor (2003) similarly used collaborative efforts to form a health advisory group to identify key areas to target in a nutrition program for pregnant women.

Main Theme 3: Use of a Theoretical Model in Program Development. Six of the fifteen interventions used the Stages of Change Theory to guide program development. The programs using Stages of Change reported significant improvements primarily in healthy eating and overall nutrition knowledge. For instance, Havas et al. (2003) used the Intent to Treat philosophy as well as the Stages of Change model. Data were gathered at baseline, two months after the intervention, and one year after the intervention. One third of participants were in the precontemplation stage of change whereas one fourth was in the contemplation stage. The use of the model assisted program planners and developers with the overall delivery of the intervention, appropriateness of the intervention and evaluation of program efforts. Bhargava and Hays (2004) employed Social Learning Theory as the framework for the Women's Health Trial: 
Feasibility Study in Minority Populations (WHTFSMP), a nutrition education program delivered to African-American and Hispanic low income women. Results showed that the intervention group was significantly more likely than the control group to score lower on the Unhealthy Eating Index $(p<.05)$. Intakes of saturated and monosaturated fat were significantly associated with high scores on the Unhealthy Eating Index $(p<.05)$. Additionally, Heneman et al. (2005) assessed the use of a written contract in increasing fruit and vegetable consumption. Results indicated that the contract group exhibited more movement in vegetable consumption based on the Stages of Change model than the control group.

Main Theme 4: Focus on Learner-Centered and Individualized Approaches. Learner-centered approaches, such as individualized counseling, were found to be effective in dietary behavior change. Several interventions utilized such approaches, resulting in successful changes.

Compared to group interventions, individual approaches were found to be more effective in increasing nutrition knowledge and behaviors among this population. Cason, Scholl, and Kassab (2002) examined the impact of EFNEP on eating patterns using three differing types of program delivery: individual, group, and SuperCupboard, which consisted of basic life skills education as well as food safety, preparation, resource management, and nutrition education. SuperCupboard targets individuals who regularly utilize emergency food services. Researchers employed a pretest-posttest research design with a 24-hour dietary recall and dietary habits surveys. A total of 2,059 participants completed pretests and posttests. Approximately $70 \%$ of participants were enrolled in the group program, $17 \%$ were in the SuperCupboard program, $10 \%$ were in the individual group, and $2 \%$ participated in both the group and individual program. Results indicated that individual program delivery participants were significantly more likely than SuperCupboard participants to eat an increased number of meals $(p<.001)$, servings of dairy $(p<.001)$, servings of fruit $(p$ $<.001)$, milligrams of iron $(\mathrm{p}<.05)$, milligrams of calcium $(p<.001)$, milligrams of vitamin B6 $(\mathrm{p}<.001)$, and grams of fiber $(\mathrm{p}=.003)$. Additionally, individual program delivery participants were significantly more likely than group delivery participants to eat an increased number of meals $(\mathrm{p}<.001)$, servings of dairy $(\mathrm{p}$ $<.001)$, servings of fruit $(\mathrm{p}<.001)$, milligrams of calcium $(\mathrm{p}<.001)$, vitamin A $(\mathrm{p}<.019)$, vitamin $C(p<.002)$, and vitamin B6 $(p<.004)$. The traditional group participants were significantly more likely than SuperCupboard participants to eat more vegetables $(p=.04)$, milligrams of vitamin B6 $(\mathrm{p}=.018)$, and grams of fiber $(\mathrm{p}=.041)$. Finally, SuperCupboard participants were significantly more likely than individual participants $(\mathrm{p}=.015)$ or group participants $(p=.003)$ to eat more servings of food from the "other group." Recommendations offered by the researchers included training educators on learner-centered approaches in group settings. Furthermore, the researchers recommended enhancing group programs by introducing more individualistic strategies such as individual meetings, telephone calls, discussions and additional group sessions. Additional research should focus on the cost effectiveness of group programs versus individual programs as well as methods of enhancing all three techniques to increase retention and improve program effectiveness. Future nutrition interventions aimed at low income women may wish to focus their efforts on learner-centered approaches.

Main Theme 5: Use of Skills-Based Approaches to Enhance Knowledge and Self-Efficacy. Teaching specific and practical skills on how to eat healthy and how to make healthy nutritional decisions increases the likelihood that educational information will be taken from the classroom/facility site to the actual home and used in everyday life. Boyd and Windsor (2003) educated low income pregnant women about overall health knowledge in conjunction with specific skills such as how to solve health problems, how to make healthy decisions, how to practice healthy dietary habits, how to garner friendship for social support and how to have fun in eating healthy. Results showed significant improvements in dietary knowledge and behaviors. Birmingham, Shultz, and Edelfsen (2004) examined the effectiveness of a five-a- 
day for better health educational and recipe booklet for women enrolled in WIC. After reading the booklet and learning specific skills, participants reported feeling more confident about choosing quality fresh produce (70\%), properly storing both vegetables and fruits $(68 \%)$, and reported it was easier to incorporate vegetables and fruits into meals (74\%). Women who reported confidence in choosing fruits and vegetables were also significantly more confident in incorporating fruits and vegetables into meal time $(p<.0001)$ and to report that adult family members were willing to try new types of fruits and vegetables $p<.05$ ). Skills were noted in helping women to overcome the high cost of fresh fruits and vegetables. Results showed that $65 \%$ felt it was more expensive to eat fresh fruits and vegetables than frozen or canned produce.

Main Theme 6: Use of Coupons to Purchase Healthy Foods. Programs provided coupons and produce supplements to participants to purchase fresh fruit and vegetables. Many programs focused specifically on increasing fresh fruit and vegetable purchasing and consumption. Such a focus differed from those primarily seeking to increase knowledge of nutritional concepts and benefits of healthy eating. Birmingham, Shultz, and Edelfsen (2004), for instance, examined potential barriers to women's adoption of healthy eating habits and found that cost was a major concern. The authors recommended utilizing additional WIC programs and incentives to increase healthy food consumption. Similarly, Herman, Harrison, and Jenks (2006) assessed the impact of vouchers supplied to low income women on fruit and vegetable purchases. The provided vouchers were redeemable at a supermarket, a farmers' market, and a control site. Results indicated that voucher redemption rates were approximately $90 \%$ for the farmers' market and $87 \%$ for the supermarket. Overall, the vouchers increased fruit and vegetable consumption among the intervention participants.

An additional intervention assessed the effects of coupons for a Farmers' Market Nutrition Program on fruit and vegetable consumption (Anderson, ByBee, Brown, McLean, Garcia,
Breer, \& Schillo, 2001). Women were placed into one of four groups including nutrition education and coupons, education only, coupons only, and control. Women receiving both nutrition education and coupons for fresh produce demonstrated the most improvement in consumption of fruits and vegetables and attitudes toward consumption. Results suggest that a combination of coupons and nutrition education may be the most effective method of increasing fruit and vegetable consumption as well as improving attitudes toward healthy eating habits.

Main Theme 7: Use of Computer-Based Interventions. Four interventions were computer-based. Each study found positive differences in eating behaviors after the program ended. The effective use of computers with this population is quite interesting and possibly surprising to some since many low income women lack access to computers outside of a clinic setting. Nevertheless, the use of computers inside of clinics and providing women with free access to computers was efficacious. Campbell, et al. (2004) evaluated a CD-ROM nutrition education program among WIC eligible, low income females. FoodSmart is a computer-based program, which tailors nutrition education messages to its users, utilized by two different WIC clinics in North Carolina. The research objectives included improving parent's knowledge of prenatal, infant, child nutrition, and feeding, improving knowledge of healthful food choices for disease prevention, improving overall self-efficacy for choosing healthy foods, and improving dietary behaviors (i.e., lowering fat, increasing fruit and vegetable consumption). Study inclusion criteria included women at least 18 years of age, receiving WIC benefits for themselves and their children, and able to speak and understand English. Pregnant women were included as long as they were deemed low risk and had an initial consultation with a nutrition counselor. Once researchers collected informed consent, participants were randomized into intervention or control groups by a computer. The intervention was based on the Social Cognitive Theory and the Transtheoretical Model. The actual intervention consisted of a video soap opera utilizing persuasion and 
modeling positive dietary behavior changes. In addition, infomercials support the soap opera message by providing information on healthy eating as well as infant feeding practices. Immediate feedback regarding current eating habits and strategies to improve those behaviors were given to participants via the computer. Participants entered information into the computer using a touch screen. Additionally, audio narration was provided to aid women with low literacy levels. The study design utilized a pretest-posttest design, in which intervention and control groups completed questionnaires including a Food Frequency Questionnaire (FFQ), the Block survey, as well as items on self-efficacy, nutrition knowledge, and stages of change. Participants were also requested to complete a one-month follow-up. However, few participants returned for the one-month followup, thus, researchers decided to contact participants by telephone. Overall, there was a $74.8 \%$ response rate $(\mathrm{N}=307)$. The intervention group was significantly more likely than the control group to correctly answer knowledgebased questions $(\mathrm{p}=.02)$. Intervention groups showed significant increases in self-efficacy scores $(\mathrm{p}<.01)$. Regarding eating behaviors, intervention group was significantly more likely than control group to consume low-fat dairy products at one month follow-up $(\mathrm{p}<.05)$. Regarding stages of change, those in action and maintenance stages consumed the least amount of fat. Precontemplation stage was correlated to the highest amount of fat consumption. Study limitations included two different types of data collection methods. The study materials were written in English; therefore, non-English speaking women were eliminated from study participation. Implications for practice include the ability to implement a nutrition education program within the WIC setting. Health professionals may need to work to find methods of implementing similar programs in health clinics or motivate low income participants to use computer-based programs over time.

Additionally, Block et al. (2004) assessed the effects of a brief, CD-ROM program, Little By Little, a computer-based nutrition education program, on fruit and vegetable consumption. A total of 481 low income women participated in a randomized control trial, which consisted of a one time intervention with the CD-ROM program, the one-time intervention and two reminder phone calls, and a stress management CD-ROM. Baseline data and follow-up dietary intake was collected via a modified 24-hour dietary recall. Overall, fruit and vegetable consumption increased in both intervention groups. In fact, the Little by Little CD-ROM group with follow-up phones calls increased their daily intake of fruits and vegetables by 1.32 , which is greater than $86 \%$ more than the control group. The Little by Little CD-ROM group without follow-up phone calls reported a daily increase of 1.20 fruits and vegetables, which is $69 \%$ more than the control group. Similarly, Brinberg and Axelson (2002) evaluated a small-scale intervention of tailored educational messages aimed at increasing positive nutrition attitudes and behaviors among low income pregnant women. Overall, the intervention was designed to modify nutrition consumption of low income pregnant women at nutritional risk. The intervention group received a tailored message via a computer based on selfreported questionnaire responses whereas the control group received a standardized nutrition message, which included nutrition assessment, counseling and a brief nutrition and pregnancy video. Results indicated that women in the intervention group were significantly more likely than the control group to consume the targeted foods and significantly less likely to experience no change in eating behaviors from pretest to posttest.

Main Theme 8: Use of Culturally-Based and Culturally-Appropriate Programs. Three interventions focused on cultural competency as a critical element of their program (Auslander, Haire-Joshu, Houston, Rhee, \& Williams, 2002; Ikeda et al., 2002; Williams, Auslander, de Groot, Robinson, Houston, \& Haire-Joshu, 2006). For instance, Havas et al. (2003) used peers as a method of increasing cultural competency of materials and information presented in the nutrition intervention. Each of these interventions resulted in increases in healthy eating among the women participants. Ikeda et al. (2002) targeted their nutritional education program toward Vietnamese women 
immigrants in the US. A culturally appropriate and culturally sensitive intervention was developed specifically to meet the needs of this population. Educational components were translated into Vietnamese and a particular focus was placed on the healthy aspects of a Vietnamese diet, which is typically low in fat and high in fruits, vegetables, and carbohydrates. Results of this intervention showed significant improvements in following recommended dietary guidelines, as compared against the control group. Consumption of calcium, riboflavin, vitamin $\mathrm{B}$, and potassium also increased. The authors noted the importance of using bilingual health professionals and volunteers to deliver programs when working with non-English speaking populations. In addition, nutrition materials should be culturally appropriate and offered in the target population's native language. Such steps increases program adherence, effectiveness and overall reach of the intervention.

Williams, Auslander, de Groot, Robinson, Houston, and Haire-Joshu (2006) examined the cultural relevance of a nutrition education and diabetes prevention program, Eat Well Live Well Nutrition Program, for African-American women. Researchers utilized the Stages of Change Theory to develop the program and examined data from 152 women to assess cultural relevancy of the program and to identify possible links between cultural relevancy and changes in dietary behaviors. In this study, cultural relevancy was significantly associated with increases in positive dietary behaviors $(p$ $<.01)$ and program satisfaction $(\mathrm{r}=.61), \mathrm{p}<$. 001). Specifically, cultural relevancy was associated with avoiding fat as a seasoning $(\mathrm{p}$ $<.01)$ and avoiding fried foods $(\mathrm{p}<.01)$. In addition, from pretest to posttest, within group results indicate intervention participants significantly increased low-fat food intake ( $\mathrm{p}$ $<.001$ ). At posttest, most intervention participants moved from preparation stage to action stage $(10.5 \%, 89.5 \% ; \mathrm{p}<.02)$. Overall, intervention participants reported consuming significantly lower calories from fat $(35.6 \%$, $31.78 \%$ ). The authors recommended that health professionals create culturally relevant programs for African-American populations.
Main Theme 9: Use of Peer Teaching. Three interventions utilized peer teaching strategies to enhance healthy eating among women. Each of these interventions found significant differences in eating behaviors. Auslander, Haire-Joshu, Houston, Rhee, and Williams (2002) used peer teaching to deliver the community-based nutrition education program entitled, Eat Well Live Well Nutrition Education program. Peer educators delivered curricular information on healthy dietary habits to low income AfricanAmerican women. Pretest, posttest and threemonth follow-up survey results from this casecontrol study found that the intervention group was significantly more likely than the control group to show significant increases $(\mathrm{p}<.0001)$ in fat-related knowledge, skill-related knowledge, low-fat food consumption and the reduction of overall fat consumption in their diets. Havas et al. (2003) similarly used peer educators to deliver nutritional education to low income women at ten WIC sites in Maryland.

Main Theme 10: Emphasis placed on social support and increased physical activity along with dietary changes. To sustain positive nutrition behavioral change over time, attention should also be devoted to social support and involvement in physical activity. In the community-based Eat Well Live Well Nutrition Education program aimed at low income African-American women, Auslander, HaireJoshu, Houston, Rhee, and Williams (2002) stressed that programs should encourage increased regular physical activity along with an increase in fruit and vegetable intake to most effectively reduce overweight and maintain healthy weight status. Cason, Scholl, and Kassab (2002) recommend enhancing group programs by individual meetings, telephone calls, and additional group sessions. Increasing contact between facilitators and clients may enhance effectiveness and increase long-term sustainability. In addition, Boyd and Windsor (2003) found focus group participants listed friends and fun as main components of a nutrition education curriculum. Social support may motivate individuals to modify behaviors such as nutrition. 


\section{Discussion}

The present study was conducted to review literature on interventions aimed at increasing nutrition knowledge and behaviors among low income women. Of a potential 950 articles, 15 interventions that matched inclusion criteria were identified. Based on the findings of this review, ten main themes were found regarding nutrition interventions for low income women. These ten themes provide effective strategies and lessons learned from the research regarding increasing healthy eating among low income females. Such strategies may be adopted to increase the effectiveness of current and future nutrition programming.

Overall, the majority of interventions identified centered on the Women, Infants, and Children (WIC) government program or the Expanded Food and Nutrition Education Program (EFNEP). Several nutrition programs are already conducted as part of WIC and EFNEP (Birmingham, Shultz, \& Edlefsen, 2004). Research goals were, in part, aimed at evaluating or improving existing programs or developing and evaluating new nutrition interventions. Results indicated that WIC and EFNEP clients benefited from these programs and exhibited increases in fruit and vegetable consumption and improved nutrition attitudes. Additionally, WICbased interventions offer access to low income women, a population at risk for poor nutrition behaviors. Each year, WIC provides services to more than 7 million women nationwide, offering significant potential for WIC-based interventions to modify and improve nutrition behaviors (Havas et al., 2003). Currently, supplemental foods provided by WIC do not include fresh fruits and vegetables, as only juice is offered to clients as well as carrots to breastfeeding women (USDA, 2005). For this reason, researchers choose to target WIC clients with nutrition interventions specifically targeting fruit and vegetable consumption.

Several interventions provided resources to women in order to purchase more food, especially fruits and vegetables. Based on this review, such interventions, including providing coupons or vouchers for produce, may be an effective method of increasing fruit and vegetable consumption among low income women. Interventions utilizing coupons or vouchers found significant increases in fruit and vegetable consumption (Anderson et al., 2001; Birmingham, Shultz, \& Edelfsen, 2004; Herman, Harrison, \& Jenks, 2006). As aforementioned, WIC does not provide fruits and vegetables as part of its supplemental package. Coupon-based interventions were predominantly found at WIC sites to increase consumption among women who may otherwise lack access to fresh fruits and vegetables. Furthermore, coupons may be an important strategy for reducing certain barriers including cost and availability. Reducing barriers to fruit and vegetable consumption is an important method of increasing produce intake among low income women (Cohen, Stoddard, Saroughkhanians, \& Sorensen, 1998; Quan, Salomon, Nitzke, \& Reicks, 2000).

Theoretical frameworks including Stages of Change, Patient Empowerment Theory, and Intent to Treat Theory comprised many of the nutrition interventions. All theoretically based programs found increases in nutrition knowledge, attitudes, or behaviors. A total of four interventions utilized the Stages of Change Model, which suggests that behavior modification occurs over a series of six stages (Prochaska, Redding, \& Evers, 1997). The Stages of Change model is appropriate for nutrition interventions, as it promotes individual changes in nutrition while also considering additional variables such as socioeconomic status (Clark \& McElroy, 1995; Rudd \& Comings, 1994). Studies employing this theory focused on moving women from precontemplation, currently not considering behavior change, into the action stage, currently implementing positive eating behaviors. Each of these studies demonstrated significant increases in positive dietary behavior change. Of these studies, two chose an additional theoretical framework to complement Stages of Change Theory. One study employed the Social Cognitive Theory whereas the other study employed Intent to Treat Theory to complement Stages of Change Theory and further tailor the program to the target population. An additional 
study, utilizing Social Learning Theory found significant reductions on participants' Unhealthy Eating Index scores. Next, one intervention was developed based on the Patient Empowerment Theory and resulted in significant increases in calcium, potassium, riboflavin, and vitamin B.

In this review, a surprising number of programs failed to utilize theories in their nutrition programs. Theory is a useful tool in developing and evaluating nutrition interventions as it provides health professionals with a basic understanding of human behaviors (National Institutes of Health, 2005). Theories can also guide program methods that effectively reach the target population while also explaining reasons individuals choose to engage in positive or negative behaviors.

Based on the findings, learner-centered approaches, such as individual counseling, may be effective in dietary behavior change. Several interventions utilized this approach and contributed to this finding. Individual interventions were more effective in increasing nutrition knowledge and behaviors than group interventions. Nutrition interventions aimed at low income women may want to focus on learner-centered approaches. Additionally, in this review, many women-focused nutrition interventions view the female in the role of mother. It seems researchers are attempting to impact the mother, or female head of the household, in order to impact the family. Previous research indicates women are often the focus of nutrition interventions due to the possible impact on family eating habits (Harnack, Story, Martinson, Neumark-Sztainer, \& Stang, 1998). Nutrition interventions may be more effective if they concentrate solely on behavior change of the program participants.

In this review, the interventions provide additional evidence for collaboration among agencies and for skill-based approaches. Collaboration with community agencies increased program effectiveness in several interventions. Collaborative approaches foster community ownership and participation (Auslander, Haire-Joshu, Houston, Williams, \& Krebill, 2000). Perhaps low income women are more receptive to programs associated with local or community-based agencies. Additionally, skill-based approaches provide participants with opportunities for personal growth and development rather than supplying participants with a direct service (Auslander et al., 2000). Skill-building may be particularly important in nutrition interventions as participants need skills such as making healthy food choices to improve dietary habits. Skill-based approaches may impact long-term effectiveness of nutrition interventions. Follow-up evaluations could provide insight into long-term effectiveness of the programs.

Several interventions provided nutrition education via a computer. One benefit of computer-based approaches is tailoring nutrition messages to the specific needs of an individual participant. Rather than general nutrition education, computer-based education provides targeted information and education based on individual's responses to computer-generated questions. Thus, individualized education is provided, which may increase the effectiveness of the program. In this review, no published study was identified that compared the effectiveness of computer-based education with more traditional education programs. Such an evaluation could shed light on the most effective methods of education with low income women. In addition, computer-based programs can be delivered with little staff involvement. This is particularly important for WIC-based programs as client to staff ratio is approximately 300:1 (United States General Accounting Department, 2000). In such a setting, computers are a practical method of delivering nutrition education.

Specific to programming, certain strategies may be effective for low income women. Several interventions utilized peer teaching methods to educate low income women regarding nutrition and healthy eating. Employing peer teaching in nutrition education may ensure that all materials and programming are culturally competent for the target audience (Havas et al., 2003). As culturally competent nutrition education programs contribute towards effectiveness, peer teaching may enhance cultural competence, 
thereby increasing program success. Future research regarding potential associations between peer teaching and cultural competence is warranted. Additionally, previous research suggests a strong association between client satisfaction and culturally appropriate programming (Brisco \& Pichert, 1999). Such satisfaction may influence both participation and retention and increase the overall success of the intervention. All nutrition interventions should examine cultural competency in all stages of programming including development, implementation, and evaluation.

From this review, an emerging theme focused on increasing social support and physical activity in combination with nutrition education. Recommendations from many studies included focusing on social support and physical activity in future educational programs. Auslander et al. (2002) recommended offering physical activity to increase health benefits such as weight loss or chronic disease prevention. A combination of physical activity and nutrition modification may yield greater health benefits to participants than nutrition education alone. Additionally, increasing social support was suggested by many authors as a method of increasing program effectiveness. Research indicates that women perceive lack of social support as a significant barrier in improving dietary behaviors (Parker \& Keim, 2004). Group programs were often enhanced by telephone calls, face to face meetings, and supplemental group meetings. These additional methods of support may have contributed to overall program success. Future evaluations should assess the association between social support and program effectiveness.

\section{Points of Concern}

Most of the reviewed interventions provided nutrition education to low income women in a group or community setting such as a WIC office. In such a setting, women with children may lack adequate day care or child care services in order to take advantage of many of the programs. No study found in this review mentioned day care or child care services to assist the women participants while attending the education program. Additionally, retention was a significant issue with the majority of interventions reviewed. Perhaps, offering child care services would increase both participation rates as well as retention rates. Additionally, WIC-based nutrition education excludes low income women who do not have children. Programs focusing on low income women in other sites, such as churches and community centers, should be developed and evaluated for effectiveness.

\section{Limitations to the Review}

Limitations to this review should be noted. This paper presents a narrative review and not a quantitative meta-analysis. Discussion on aspects such as effect sizes, correlation coefficients, and other quantitative measures cannot be ascertained from this review.

\section{Recommendations for Nutrition Education Programs}

Nutrition educators should incorporate the aforementioned themes into programs aimed at low income women. WIC and ENEFP are important sites for nutrition education as these sites allow for access to low income women. Additional sites such as churches or community centers should also be utilized to expand the reach of such programs to low income women without children. Research on nutrition education supports learner-centered, theorybased, and culturally competent programs as the foundation for solid and effective programming. Collaborative approaches should also be utilized as this approach was found to be effective. Additionally, strategies such as peer teaching, using technology such as computers or CDROM, and building skills can enhance any nutrition education program. 


\section{References}

Anderson, J. V., ByBee, D. I., Brown, R. M., McLean, D. F., Garcia, E. M., Breer, L., \& Schillo, B. A. (2001). 5-A-Day fruit and vegetable intervention improves consumption in a low income population. Journal of the American Dietetic Association, 101, 195-202.

Auslander, W., Haire-Joshu, D., Houston, C., Rhee, C. W., \& Williams, J. H. (2002). A controlled evaluation of staging dietary patterns to reduce the risk of diabetes in African-American women. Diabetes Care, 25, 809-814.

Auslander, W. F., Haire-Joshu, D., Williams, J. H., Houston, C., \& Krebill, H. (2000). The short-term impact of a health promotion program for African-American women. Research in Social Work Practice, 10, 56-77.

Bhargava, A., \& Hays, J. (2004). Behavioral variables and education are predictors of dietary change in the Women's Health Trial: Feasibility study in minority populations. Preventive Medicine, 38, 442-451.

Birmingham, B., Shultz, J. A., \& Edlefsen, M. (2004). Evaluation of a Five-A-Day recipe booklet for enhancing the use of fruits and vegetables in low income households. Journal of Community Health, 29, 45-62.

Block, G., Wakimoto, P., Metz, D., Fujii, M. L., Feldman, N., Mandel, R., \& Sutherland, B. (2004). A randomized trial of the Little by Little CD-ROM: Demonstrated effectiveness in increasing fruit and vegetable intake in a low income population. Preventing Chronic Disease, 1, 1-12.

Boyd, N. R., \& Windsor, R. A. (2003). A formative evaluation of in maternal and child health practice: The partners for life nutrition education program for pregnant women. Maternal and Child Health Journal, 7, 137-143.

Brinberg, D., \& Axelson, M. L. (2002). Improving the dietary status of low income pregnant women at nutritional risk. Journal of Public Policy \& Marketing, 21, 100-104.

Brisco, V. J., \& Pichert, J. W. (1999). Evaluation of a program to promote diabetes care via existing agencies in African-American communities. ABNF Journal, 10, 111-115.

Campbell, M. K., Carbone, E., Honesss-Morreale, L., Heisler-MacKinnon, J., Demissie, S., \& Farrell, D. (2004). Randomized trial of a tailored nutrition education CD-ROM program for women receiving food assistance. Journal of Nutrition Education and Behavior, 36, 58-66

Cason, K. L., Scholl, J. F., \& Kassab, C. (2002). A comparison of program delivery methods for low income nutrition audiences. Topics in Clinical Nutrition, 17, 63-73.

Centers for Disease Control and Prevention. (2006). Physical activity and good nutrition: Essential elements to prevent chronic diseases and obesity. Retrieved October 8, 2006, from http://www.cdc.gov/nccdphp/publications/aag/dnpa.htm

Centers for Disease Control and Prevention (1999). Chronic diseases and their risk factors: The nation's leading causes of death. Atlanta: Author.

Clark, N., \& McElroy, K. (1995). Creating capacity through health education: What we know and what we don't. Health Education Quarterly, 22, 273-289

Cohen, N. L., Stoddard, A. M., Saroughkhanians, S., \& Sorensen, G. (1998). Barriers toward fruit and vegetable consumption in a multiethnic worksite population. Journal of Nutrition Education, 30, 381-386.

Conrey, E. J., Frongillo, E. A., Dollahite, J. S., \& Griffin, M. R. (2003). Integrated program enhancements increased utilization of farmers' market nutrition program. The Journal of Nutrition, 133, 1841-1844.

Drewnowski, A. (2003). Fat and sugar: An economic analysis. The Journal of Nutrition, 133, 838S-840S.

Drewnowski, A., \& Specter, S. (2004). Poverty and obesity: the role of energy density and energy costs. The American Journal of Clinical Nutrition, 79, 6-16.

Drewnowski, A., Darmon, N., \& Briend, A. (2004). Replacing fats and sweets with vegetables and fruit: A question of cost. American Journal of Public Health, 94, 1555-1559.

Drewnowski, A., \& Darmon, N. (2005). Food choices and diet costs: An economic analysis. The Journal of Nutrition, 135, 900-904. 
Giskes, K., Turrell, G., Patterson, C., \& Newman, B. (2002). Socioeconomic differences among Australian adults in consumption of fruit and vegetables and intakes of vitamins A, C, and folate. Journal of Human Nutrition and Dietetics, 15, 375-385.

Groth, M. V., Fagt, S., \& Bronsted, L. (2001). Social determinants of dietary habits in Denmark. European Journal of Clinical Nutrition, 55, 959-966.

Harnack, L., Story, M., Martinson, B., Neumark-Sztainer, D., \& Stang, J. (1998). Guess who's cooking? The role of men in meal planning, shopping, and preparation in US families. Journal of the American Dietetic Association, 98, 995-1000.

Havas, S., Anliker, J., Greenberg, D., Block, G., Block, T., Blik, C., et al. (2003). Final results of the Maryland WIC food for life program. Preventive Medicine, 37, 406-416.

Heneman, K., Block-Joy, A., Zidenberg-Cherr, S., Donohue, S., Garcia, L., Martin, A., et al. (2005). A "Contract for Change" increases produce consumption in low income women: A pilot study. Journal of the American Dietetic Association, 105, 1792-1796.

Herman, D. R., Harrison, G. G., \& Jenks, E. (2006). Choices made by low income women provided with an economic supplement for fresh fruit and vegetable purchase. Journal of the American Dietetic Association, 106, 740-744.

Hulshof, K. F., Brussaard, J. H., Kruizinga, A. G., Telman, J., \& Lowik, M. R. (2003). Socio-economic status, dietary intake and 10 year trends: The Dutch National Food Consumption Survey. European Journal of Clinical Nutrition, 57, 128-137.

Ikeda, J. P., Phan, L., Nguyen, K. P., \& Mitchell, R. A. (2002). Culturally relevant nutrition education improves dietary quality among WIC-eligible Vietnamese immigrants. Journal of Nutrition Education \& Behavior, 34, 151-158.

Irala-Estevez, J. D., Groth, M., Johansson, L., Oltersdorf, U., Prattala, R., \& Martinez-Gonzalez, M. A. (2000). A systematic review of socioeconomic differences in food habits in Europe: Consumption of fruits and vegetables. European Journal of Clinical Nutrition, 54, 706-714.

Kirkpatrick, S., \& Tarasuk, V. (2003). The relationship between low income and household food expenditure patterns in Canada. Public Health Nutrition, 6, 589-597.

Lallukka, T., Laaksonen, M., Rahkonen, O., Roos, E., \& Lahelma, E. (2007). Multiple socio-economic circumstances and healthy food habits. European Journal of Clinical Nutrition, 61, 701-710.

Martikainen, P., Brunner, E., \& Marmot, M. (2003). Socioeconomic differences in dietary patterns among middle-aged men and women. Social Science \& Medicine, 56, 1397-1410.

McCullough, M. L., Feskanich, D., Stampfer, M. J., Giovannucci, E. L., Rimm, E. B., Hu, F. B., et al. (2002). Diet quality and major chronic disease risk in men and women: Moving toward improved dietary guidance 1-3. American Journal of Clinical Nutrition, 76, 1261-1271.

National Center for Health Statistics. (2006). Prevalence of overweight and obesity among adults: United States, 2003-2004. National Health and Nutrition Examination Survey. Retrieved October 8, 2006, from http://www.cdc.gov/nchs/products/pubs/pubd/hestats/obese03 04/overwght adult 03.htm

National Institutes of Health. (2005). Theory at a glance: A guide for heath promotion practice (2nd ed.). Retrieved June 15, 2008, from http://www.nci.nih.gov/PDF/481f5d53-63df-41bcbfaf-5aa48ee1da4d/TAAG3.pdf

Parker, S., \& Keim, K. S. (2004). Emic perspectives of body weight in overweight and obese white women with limited income. Journal of Nutrition Education and Behavior, 36, 282-289.

Prochaska, J. P., Redding, C. A., \& Evers, K. E. (1997). The transtheoretical model and stages of change. In K. Glanz, F. Lewis, \& Rimer, B. (Eds.), Health behavior and health education: Theory, research, and practice (2nd ed.) (pp. 60-84). San Francisco: Josey-Bass.

Quan, T., Salomon, J., Nitzke, S., \& Reicks, M. (2000). Behaviors of low income mothers related to fruit and vegetable consumption. Journal of the American Dietetic Association, 100, 567-570.

Rudd, R., \& Comings, J. (1994). Learner developed materials: An empowering product. Health Education Quarterly, 21, 313-327. 
Shahar, D., Shai, I., Vardi, H., Shahar, A., \& Fraser, D. (2005). Diet and eating habits in high and low socioeconomic groups. Nutrition, 21, 559-566.

Tarasuk, V., McIntyre, L., \& Li, J. (2007). Low income women's dietary intakes are sensitive to the depletion of household resources in one month. The Journal of Nutrition, 137, 1980-1987.

United States Department of Health and Human Services. (2001a). Healthy people 2010: Understanding and improving health (2nd ed.). Washington, DC: Government Printing Office.

United States Department of Health and Human Services. (2001b). The Surgeon General's call to action to prevent and decrease overweight and obesity. Washington DC: Government Printing Office.

United States Department of Health and Human Services. (2005). Dietary guidelines for Americans. Retrieved October 10, 2006, from http://www.health.gov/dietaryguidelines/dga2005/document/

United States General Accounting Office. Food assistance: Activities and use of nonprogram resources at six WIC agencies. Washington DC: Author.

Willet, W. C., Sacks, F., Trichopoulou, A., Drescher, G., Ferro-Luzzi, A., Helsing, E., \& Trichopoulos, D. (1995). Mediterranean diet pyramid: A cultural model for health eating. The American Journal of Clinical Nutrition, 61(Suppl.), 1402S-1406S.

Williams, J. H., Auslander, W. F., de Groot, M., Robinson, A. D., Houston, C., \& Haire-Joshu, D. (2006). Cultural relevancy of a diabetes prevention nutrition program for African-American women. Health Promotion Practice, 7, 56-67.

\author{
Author Information \\ Rebecca A. Vidourek, MEd, CHES* \\ Graduate Assistant \\ Health Promotion and Education Program \\ University of Cincinnati \\ P.O. Box 210068, 526 TC \\ Cincinnati, OH 45221-0068 \\ $\mathrm{Ph}:$ 513-556-3859 \\ Fax.: 513-556-3898 \\ E-Mail: vidourra@email.uc.edu \\ Keith A. King, PhD, CHES \\ Associate Professor \\ Health Promotion and Education Program \\ University of Cincinnati \\ Cincinnati, OH 45221-0068 \\ E-Mail: keith.king@uc.edu \\ * corresponding author
}




\section{Appendix A}

Summary of Nutrition Programs Meeting Criteria for Study Inclusion

\begin{tabular}{|c|c|c|c|c|c|}
\hline Study & $\begin{array}{l}\text { Sample Size and } \\
\text { Description }\end{array}$ & $\begin{array}{l}\text { Theory or Model } \\
\text { Used in Program }\end{array}$ & $\begin{array}{c}\text { Intervention } \\
\text { Description } \\
\end{array}$ & Duration & Major Findings \\
\hline $\begin{array}{l}\text { FoodSmart, CD-ROM } \\
\text { based nutrition education }\end{array}$ & $\begin{array}{l}307 \text { intervention and } \\
\text { control participants }\end{array}$ & $\begin{array}{l}\text { Stages of Change } \\
\text { and Social } \\
\text { Cognitive Theory }\end{array}$ & $\begin{array}{l}\text { To increase healthy } \\
\text { eating habits among } \\
\text { WIC eligible women }\end{array}$ & Three months & $\begin{array}{l}\text { Significant increase in consumption } \\
\text { of low fat dairy products, knowledge, } \\
\text { and self efficacy }\end{array}$ \\
\hline $\begin{array}{l}\text { Dietary behaviors of } \\
\text { Vietnamese immigrants }\end{array}$ & $\begin{array}{l}152 \text { intervention and } \\
\text { control participants }\end{array}$ & $\begin{array}{l}\text { Patient } \\
\text { Empowerment }\end{array}$ & $\begin{array}{l}\text { Culturally appropriate } \\
\text { education to improve } \\
\text { diets of Vietnamese } \\
\text { immigrants }\end{array}$ & 1993 to 1996 & $\begin{array}{l}\text { Significant increases in calcium, } \\
\text { potassium, riboflavin, and vitamin B. }\end{array}$ \\
\hline $\begin{array}{l}\text { Women's Health Trial: } \\
\text { Feasibility Study in } \\
\text { Minority Populations }\end{array}$ & $\begin{array}{l}866 \text { African-American } \\
\text { and Hispanic } \\
\text { participants }\end{array}$ & $\begin{array}{l}\text { Social Learning } \\
\text { Theory }\end{array}$ & $\begin{array}{l}\text { Education program } \\
\text { aimed at improving } \\
\text { eating behaviors of } \\
\text { African-American and } \\
\text { Hispanic women }\end{array}$ & 1991 to 1995 & $\begin{array}{l}\text { Significantly lower scores on } \\
\text { Unhealthy Eating Index }\end{array}$ \\
\hline $\begin{array}{l}\text { Five-A-Day for Better } \\
\text { Health Recipe Booklet }\end{array}$ & $\begin{array}{l}225 \text { intervention } \\
\text { participants }\end{array}$ & None & $\begin{array}{l}\text { Impact of a fruit and } \\
\text { vegetable booklet on } \\
\text { improving consumption } \\
\text { among low income } \\
\text { women }\end{array}$ & Two months & $\begin{array}{l}\text { Significantly more likely to feel } \\
\text { confident in ability to store fruits and } \\
\text { vegetables properly; More confident } \\
\text { incorporating fruits and vegetables } \\
\text { into mealtime. }\end{array}$ \\
\hline $\begin{array}{l}\text { Expanded Food and } \\
\text { Nutrition Program }\end{array}$ & $\begin{array}{l}2059 \text { intervention and } \\
\text { control participants }\end{array}$ & None & $\begin{array}{l}\text { Improving eating } \\
\text { behaviors while } \\
\text { comparing three } \\
\text { different methods of } \\
\text { delivery }\end{array}$ & $\begin{array}{l}\text { No timeline } \\
\text { provided }\end{array}$ & $\begin{array}{l}\text { Individual, learner-centered } \\
\text { participants showed significant gains } \\
\text { in healthy eating behaviors }\end{array}$ \\
\hline $\begin{array}{l}\text { WIC-based Food for Life } \\
\text { Program }\end{array}$ & $\begin{array}{l}2066 \text { intervention and } \\
\text { control participants }\end{array}$ & $\begin{array}{l}\text { Intent to Treat and } \\
\text { Stages of Change }\end{array}$ & $\begin{array}{l}\text { Interactive nutrition } \\
\text { education as well as } \\
\text { written materials } \\
\end{array}$ & Six months & $\begin{array}{l}\text { Reduction in calories from fat, } \\
\text { increase in fruit, vegetable, and fiber } \\
\text { intake }\end{array}$ \\
\hline $\begin{array}{l}\text { WIC-based nutrition } \\
\text { education for pregnant } \\
\text { women }\end{array}$ & 120 participants & None & $\begin{array}{l}\text { Eight nutrition } \\
\text { education sessions }\end{array}$ & 19 weeks & $\begin{array}{l}\text { Increase in knowledge and healthy } \\
\text { eating behaviors }\end{array}$ \\
\hline
\end{tabular}




\section{Appendix A (continued)}

Summary of Nutrition Programs Meeting Criteria for Study Inclusion

\begin{tabular}{|c|c|c|c|c|c|}
\hline Study & $\begin{array}{l}\text { Sample Size and } \\
\text { Description }\end{array}$ & $\begin{array}{l}\text { Theory or Model } \\
\text { Used in Program }\end{array}$ & Intervention Description & Duration & Major Findings \\
\hline $\begin{array}{l}\text { WIC-based Farmer's } \\
\text { Market Nutrition } \\
\text { Education Program }\end{array}$ & $\begin{array}{l}\text { No participant } \\
\text { information provided }\end{array}$ & None & $\begin{array}{l}\text { Coupons for Farmer's } \\
\text { Market sent to WIC } \\
\text { eligible women }\end{array}$ & 1996 to 2001 & $\begin{array}{l}\text { Increase of } \$ 122,931- \\
\$ 316,754 \text { was spent on fruits } \\
\text { and vegetables after the } \\
\text { changes were made to the } \\
\text { program }\end{array}$ \\
\hline $\begin{array}{l}\text { Eat Well Live Well } \\
\text { Nutrition Education } \\
\text { Program }\end{array}$ & $\begin{array}{l}294 \text { African- } \\
\text { Americans }\end{array}$ & Stages of Change & $\begin{array}{l}\text { Peer educators conducted } \\
\text { six group and six } \\
\text { individual nutrition } \\
\text { education programs }\end{array}$ & 3 months & $\begin{array}{l}\text { Increases in fat and skill- } \\
\text { related knowledge; Increase } \\
\text { consumption of low-fat foods }\end{array}$ \\
\hline $\begin{array}{l}\text { Eat Well Live Well } \\
\text { Nutrition Education } \\
\text { Program }\end{array}$ & $\begin{array}{l}398 \text { intervention and } \\
\text { control group } \\
\text { participants }\end{array}$ & Stages of Change & $\begin{array}{l}\text { Peer educators conducted } \\
\text { six group and six } \\
\text { individual nutrition } \\
\text { education programs }\end{array}$ & 3 months & $\begin{array}{l}\text { Cultural relevance increases } \\
\text { positive dietary behaviors and } \\
\text { program satisfaction }\end{array}$ \\
\hline $\begin{array}{l}\text { Community-based } \\
\text { Farmer's Market Nutrition } \\
\text { Education Program }\end{array}$ & $\begin{array}{l}455 \text { in intervention } \\
\text { and control groups }\end{array}$ & None & $\begin{array}{l}\text { Coupons for Farmer's } \\
\text { Market and nutrition } \\
\text { education }\end{array}$ & 5 months & $\begin{array}{l}\text { Increases in fruit consumption } \\
\text { and improve attitudes toward } \\
\text { vegetable consumptions }\end{array}$ \\
\hline $\begin{array}{l}\text { WIC-based tailored } \\
\text { computer message program }\end{array}$ & $\begin{array}{l}27 \text { intervention and } \\
\text { control participants }\end{array}$ & None & $\begin{array}{l}\text { Tailored nutrition } \\
\text { messages via a computer }\end{array}$ & $\begin{array}{l}\text { No timeline } \\
\text { provided }\end{array}$ & $\begin{array}{l}\text { Increased consumption of } \\
\text { targeted foods }\end{array}$ \\
\hline $\begin{array}{l}\text { WIC-based produce } \\
\text { vouchers }\end{array}$ & $\begin{array}{l}602 \text { intervention and } \\
\text { control participants }\end{array}$ & None & $\begin{array}{l}\text { Vouchers for Farmer's } \\
\text { Market, supermarket, and } \\
\text { control site }\end{array}$ & 6 months & $\begin{array}{l}\text { Increase in produce purchases } \\
\text { at Farmer's Market and } \\
\text { supermarket }\end{array}$ \\
\hline Contract for Change & $\begin{array}{l}38 \text { participants } \\
\text { randomized into } \\
\text { contract, intervention, } \\
\text { and control groups }\end{array}$ & Stages of Change & $\begin{array}{l}\text { Nutrition education and } \\
\text { behavior modification } \\
\text { contracts }\end{array}$ & 9 months & $\begin{array}{l}\text { Contract group showed } \\
\text { significant increases in fruit } \\
\text { consumptions }\end{array}$ \\
\hline Little By Little CD-ROM & $\begin{array}{l}481 \text { participants } \\
\text { randomized into } \\
\text { intervention and } \\
\text { control groups }\end{array}$ & Stages of Change & $\begin{array}{l}\text { One time, computer- } \\
\text { based nutrition education }\end{array}$ & 1 day & $\begin{array}{l}\text { Intervention group showed } \\
69 \% \text { increase than control } \\
\text { group in fruit and vegetable } \\
\text { consumption }\end{array}$ \\
\hline
\end{tabular}

